\title{
Short-term and long-term effect of a high-intensity pulmonary rehabilitation programme in obese patients with asthma: a randomised controlled trial
}

\author{
Yasemin Türk (1) ${ }^{1}$, Willy Theel ${ }^{2}$, Astrid van Huisstede ${ }^{1,3}$, \\ Gert-Jan M. van de Geijn ${ }^{4,5}$, Erwin Birnie ${ }^{5,6}$, Pieter S. Hiemstra (107, \\ Jacob K. Sont ${ }^{8}$, Christian Taube ${ }^{7,9}$ and Gert-Jan Braunstahl (1) ${ }^{1,10}$
}

@ERSpublications

Short-term pulmonary rehabilitation programme with high intensity interval training and internet self-management programme is feasible and improves asthma control, aerobic capacity and body weight in suboptimally controlled obese patients with asthma http://bit.ly/2mT8A9r

Cite this article as: Türk Y, Theel W, van Huisstede A, et al. Short-term and long-term effect of a highintensity pulmonary rehabilitation programme in obese patients with asthma: a randomised controlled trial. Eur Respir J 2020; 56: 1901820 [https://doi.org/10.1183/13993003.01820-2019].

\section{ABSTRACT}

Objective: To determine the short-term and long-term effects of a high intensity pulmonary rehabilitation programme on asthma control, body composition, lung function and exercise capacity in obese asthma patients.

Methods: Patients with obesity (body mass index $(\mathrm{BMI}) \geqslant 30 \mathrm{~kg} \cdot \mathrm{m}^{-2}$ ) and suboptimal controlled asthma (Asthma Control Questionnaire $(\mathrm{ACQ}) \geqslant 0.75$ ) were randomly assigned to a 3-month pulmonary rehabilitation programme ( $\mathrm{PR}$ only), pulmonary rehabilitation programme with the use of an internet based self-management support programme $(\mathrm{PR}+\mathrm{SMS})$ or usual care. The pulmonary rehabilitation programme included high-intensity interval training, nutritional intervention and psychological group sessions. Patients in the usual care group were advised to lose weight and to exercise. The primary outcome was the difference of change of ACQ between PR only and PR+SMS after 3 months. Total followup was 12 months.

Results: 34 patients were included in the study (14 PR only, nine PR+SMS, 11 control). Compared with patients in usual care, patients in the PR only group had a significant reduction in BMI and significant improvements in asthma control, exercise capacity and aerobic capacity after 3 months. These improvements persisted during 12 months of follow-up. No difference in ACQ between PR+SMS and PR only groups was observed. However, users of the SMS programme had a significantly lower BMI after 12 months compared with subjects in the PR only group.

Conclusion: A high-intensity pulmonary rehabilitation programme provides sustained improvements in asthma control, body composition and exercise capacity in obese asthmatics that are not optimally controlled and, therefore, should be considered in the treatment of these patients.

\footnotetext{
This study was registered as a clinical trial in the Netherlands Trial Registry, number NTR4322. Individual participant data that underly the results reported in this article will be available after deidentification (text, tables, figures and appendices), along with the study protocol, from 3 months and ending 5 years following article publication, to researchers who provide a methodologically sound proposal. Data will be made available for use in meta-analyses; proposals should be directed to the corresponding author.
}

This article has supplementary material available from erj.ersjournals.com

Received: 16 Sept 2019 | Accepted after revision: 16 March 2020

Copyright OERS 2020 


\section{Introduction}

Obesity is associated with an increased risk of asthma, and asthma in patients with obesity is difficult to control [1-3]. Physical inactivity is an independent risk factor for severe asthma $[4,5]$. Both asthma and obesity are associated with a decreased level of physical activity $[5,6]$. In a previous study, we demonstrated that obese adults with asthma have a lower exercise capacity compared with normal weight adults with asthma. Nevertheless, obese asthmatics were able to show similar improvements in exercise capacity and asthma control compared with non-obese asthmatics after a 12-week pulmonary rehabilitation programme. Still, a large group of obese asthmatics had no improvements from this pulmonary rehabilitation programme, which may indicate that there is need for a different approach in this group of patients [7]. In recent years, there has been increasing attention for lifestyle interventions in asthmatics with obesity. Until now, the few published studies show that a weight loss programme with exercise and dietary restriction improves asthma control and the quality of life of obese asthma patients in the short term $[8,9]$. However, information on long-term results of such programmes are still lacking. Studies in this field are urgently needed, not only to demonstrate feasibility and long-term effectiveness but also to determine the effects of different exercise modalities. High-intensity interval training (HIIT) is feasible in obese subjects and was found to be superior to medium-intensity continuous training in improving cardiopulmonary fitness (maximum exercise capacity $\left(V_{\mathrm{O}_{2} \max }\right)$ ) and in decreasing percentage body fat [10]. However, the feasibility and effectiveness of HIIT have not yet been investigated in obese subjects with suboptimal controlled asthma. In addition, data about the use of an e-health programme as a part of pulmonary rehabilitation programmes to improve long-term effectiveness is lacking. Therefore, we designed a 3-month pulmonary rehabilitation programme consisting of a combination of HIIT, a dietary intervention and a psychological intervention. In this pragmatic randomised trial, we investigated both short-term and long-term effects of this integrated pulmonary rehabilitation programme with and without the use of an internet-based self-management programme on body composition, aerobic capacity, lung function and asthma-related outcomes compared to usual asthma care in patients with obesity and suboptimal controlled asthma.

\section{Methods}

\section{Study design}

This single-centre pragmatic randomised controlled trial was conducted at the Franciscus Gasthuis and Vlietland, Rotterdam, a non-academic teaching hospital in the Netherlands. Patients were recruited from the pulmonology outpatient clinic between January 2014 and December 2016. Eligible subjects were randomly assigned to one of the intervention groups or control group: 1) pulmonary rehabilitation only ( $P R$ only), 2) pulmonary rehabilitation with online self-management support (PR+SMS), 3) usual care. There was no blinding. For randomisation details, please refer to supplementary file S1. This study was approved by the local medical research ethics committee (Toetsingscommissie Wetenschappelijk Onderzoek Rotterdam e.o; NL46602.101.13) (Netherlands Trial Registry number NTR4322).

\section{Study patients}

Subjects aged between 18 and 55 years were included if they fulfilled the criteria for obesity (body mass index $(\mathrm{BMI}) \geqslant 30 \mathrm{~kg} \cdot \mathrm{m}^{-2}$ ) and had a suboptimal controlled asthma (asthma control questionnaire score $(A C Q) \geqslant 0.75)$ despite optimal inhalation therapy (inhalation corticosteroid and a long-acting $\beta$-agonist). Asthma was diagnosed according to the Global Initiative for Asthma (GINA) guidelines [11]. Exclusion criteria are included in the supplementary file S2.

\section{Intervention}

The pulmonary rehabilitation groups ( $P R$ only and $P R+S M S$ ) participated in a 12-week pulmonary rehabilitation intervention programme including exercise training, nutritional intervention and psychological group sessions. The exercise training was a high intensity interval training session of

Affiliations: ${ }^{1}$ Dept of Pulmonology Franciscus Gasthuis \& Vlietland Rotterdam The Netherlands. ${ }^{2}$ Dept of Physiotherapy, Franciscus Gasthuis \& Vlietland, Rotterdam, The Netherlands. ${ }^{3}$ Dept of Pulmonology, Noordwest Ziekenhuisgroep, Alkmaar. The Netherlands. ${ }^{4}$ Dept of Clinical Chemistry, Franciscus Gasthuis \& Vlietland, Rotterdam, The Netherlands. ${ }^{5}$ Dept of Genetics, University Medical Center Groningen, University of Groningen, Groningen, The Netherlands. ${ }^{6}$ Dept of Statistics and Education, Francis Academy, Franciscus Gasthuis \& Vlietland, Rotterdam, The Netherlands. ${ }^{7}$ Dept of Pulmonology, Leiden University Medical Center, Leiden, The Netherlands. ${ }^{8}$ Dept of Biomedical Data Sciences, Section Medical Decision Making, Leiden University Medical Center, Leiden, The Netherlands. ${ }^{9}$ Dept of Pulmonary Medicine, University Hospital Essen - Ruhrlandklinik, Essen, Germany.

${ }^{10}$ Dept of Pulmonology, Erasmus Medical Center, Rotterdam, The Netherlands.

Correspondence: Yasemin Türk, Dept of Pulmonology, Franciscus Gasthuis \& Vlietland, Kleiweg 500, 3045 PM Rotterdam, The Netherlands. E-mail: y.turkafranciscus.nl 
40-60 min (intensity around $90 \%$ of $V_{\mathrm{O}_{2} \max }$ ), three times a week under the supervision of a physiotherapist (supplementary file S3). In addition, participants were prescribed a caloric diet of approximately $1500 \mathrm{kcal} \cdot \mathrm{day}^{-1}$ with a balanced intake of macronutrients. They were supervised by a dietician (three clinical visits and three phone calls during 12 weeks). During these visits, a healthy lifestyle was promoted, and patients were educated in a healthy diet. Psychological counselling took place during four group sessions $(1 \mathrm{~h})$. These sessions focussed on behavioural modification and motivational strategies. Subjects who were randomised to PR+SMS participated in the same programme but additionally used the internet based self-management tool "PatientCoach" (www.patientcoach.lumc.nl). For details about this programme, please refer to supplementary file S4. Subjects who were randomised to the PR+SMS group used the PatientCoach programme during 3 months of pulmonary rehabilitation and 12 months of follow-up. Subjects in the usual care group were advised to lose weight and to exercise. Total follow-up time was 1 year and all study participants were regularly seen every 3 months for assessment.

\section{Outcomes}

The primary outcome parameter was the difference of change of ACQ between PR+SMS group and PR only group after 3 months of intervention. Secondary outcomes were ACQ at 3 months between both pulmonary rehabilitation groups and the usual care group, ACQ at 12 months, asthma-related quality of life (AQLQ), lung function, physical activity level, exercise capacity, body composition, airway and systemic inflammation and exacerbation rate at 3 and 12 months of follow-up between the PR only and control groups and between the PR+SMS and PR only groups.

\section{Assessments}

Asthma control and quality of life were assessed by the validated ACQ and the AQLQ [12, 13]. Pulmonary function was measured with standard spirometry (Vmax Encore 22D; Carefusion; San Diego, CA, USA) and bodybox (Vmax encore 62j; Carefusion) according to the American Thoracic Society (ATS)/European Respiratory Society (ERS) guidelines [14]. Aerobic capacity $\left(V_{\mathrm{O}_{2} \max }\right)$ was measured with a cardiopulmonary exercise test (CPET) according to the ATS/American College of Clinical Pharmacy guidelines [15]. For a detailed description of all assessments and blood/sputum analysis, please refer to supplementary file S5 [16-23].

\section{Statistics}

Assuming a mean \pm SD effect size (difference of $\triangle \mathrm{ACQ}$ at 3 months) between $\mathrm{PR}+\mathrm{SMS}$ and $\mathrm{PR}$ only groups of $0.5 \pm 0.35$, randomisation ratio $1: 1: 1$ and adjustment for $20 \%$ drop out, at least $3 \times 12$ patients had to be included in the study. Supplementary file S6 contains descriptives and statistical analysis within the groups. Effectiveness of the pulmonary rehabilitation programme was studied by comparing outcome parameters of the PR only group versus The control group. The added value of the online self-management programme was studied by comparing the PR only and PR+SMS groups. The data of the randomised subjects were analysed according to the intention to treat principle. For the comparisons of the primary and secondary outcomes between groups at 3 months, linear regression models were used with the randomisation group, sex and the baseline variable as independent variables. Long-term (12 months) effectiveness for continuous measures was evaluated with repeated measurements analyses, with the outcome measure of interest as dependent variable and the baseline value, time, group and gender as covariables (linear mixed model, covariance structure: unstructured). To analyse the effect of BMI on asthma control (ACQ), quality of life (AQLQ), functional residual capacity (FRC) and $V_{\mathrm{O}_{2} \max }$ at 3 months and 12 months, we included $\triangle B M I$ in the regression analysis and BMI in the linear mixed model. Exacerbations at 3 months were analysed as proportions of at least one exacerbation per patient and tested with the binomial test. Long-term (12 months) effectiveness for number of exacerbations was modelled with generalised estimation equations, with the number of exacerbations as dependent variable and the baseline value, time and group as covariables (distribution: Poisson, link: Log). The beta coefficients of the poisson model were transformed in rate ratios by exponentiating the beta of the model and the confidence intervals. IBM SPSS version 22 was used for all statistical analysis. Given the exploratory character of the study, p-values were not adjusted for multiple testing. A p-value (two-sided) $<0.05$ was considered to indicate a statistically significant difference in all comparisons.

\section{Results}

\section{Participants}

A total of 112 subjects were screened for eligibility and 34 patients were randomised. 23 subjects were randomly allocated to the intervention groups (14 PR only and nine PR+SMS) and 11 subjects in the control group. Three subjects withdrew informed consent: one control patient just after randomisation, and two patients in the PR+SMS group during the pulmonary rehabilitation programme. Eventually 31 subjects were included in the intention-to-treat analysis (figure 1). Baseline characteristics of the three 


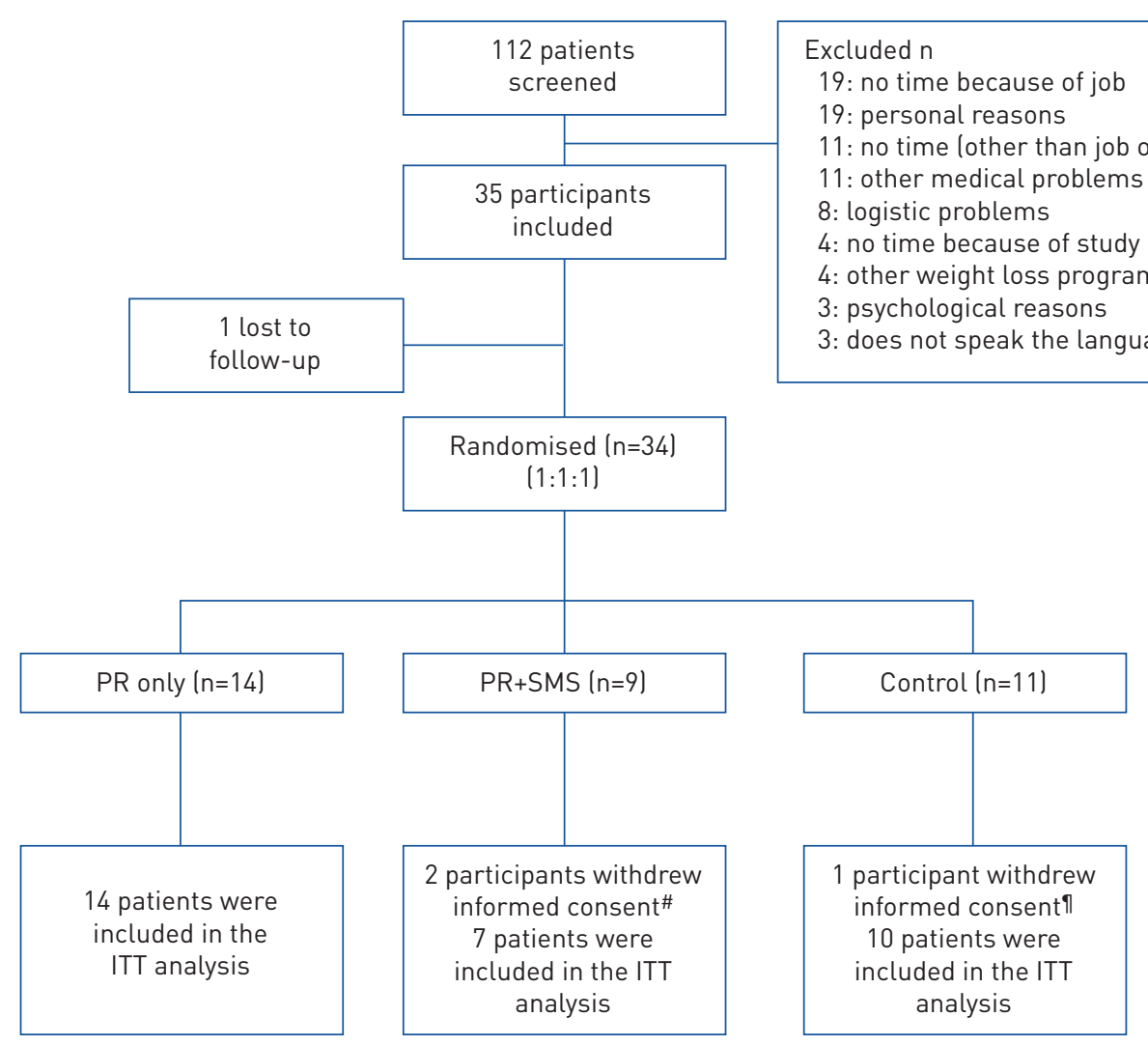

FIGURE 1 Diagram of inclusion and randomisation of study participants. \#: during the pulmonary rehabilitation programme; " : after randomisation.

groups are presented in table 1. Participants had a class II obesity (mean \pm sD BMI $36.24 \pm 4.46 \mathrm{~kg} \cdot \mathrm{m}^{-2}$ ) and a low physical fitness $\left(V_{\mathrm{O}_{2} \max } 18.25 \pm 4.64 \mathrm{~mL} \cdot \mathrm{kg}^{-1} \cdot \mathrm{min}^{-1}\right)$. All patients were using inhaled corticosteroids (ICS) and a long-acting $\mathrm{B}_{2}$ agonist (LABA). In addition, $39 \%$ of the patients were using a leukotriene receptor antagonist (LTRA) and 23\% were using a long-acting muscarinic antagonist (LAMA). Based on the criteria of the GINA guidelines of 2019 (exhaled nitric oxide fraction $\left(F_{\text {eNO }}\right)$, serum and sputum eosinophils) the majority (77\%) of the study participants had a type 2 asthma. Median (interquartile range) ACQ was $2.0(1.5-2.5)$ and $74 \%$ of the participants had an uncontrolled asthma $(A C Q \geqslant 1.5)$ at the time of randomisation.

\section{Intervention}

The median (interquartile range) compliance rate to the pulmonary rehabilitation (PR only and PR+SMS) programme was $85.7(72.0-94.4) \%$. Four patients had a compliance rate $<50 \%$. Two of these patients withdrew from the physical training programme because of knee problems originated during the training. One patient was diagnosed with a neurological disorder during the intervention period and one patient participated very irregularly to the programme for unknown reasons. Generally, HIIT was well tolerated by the participants. The most frequent complaint of patients was muscle aches in the first weeks of the training.

\section{Changes in outcomes at 3 months within groups}

The outcomes in each group are presented in table 2. In both PR only and PR+SMS groups, there was a significant reduction in weight, BMI and percentage fat mass after 3 months of pulmonary rehabilitation. Waist circumference decreased significantly in the PR+SMS group only. No reduction was observed in any of these parameters in the usual care group. Significant improvements in asthma control were observed in both intervention groups after 3 months of pulmonary rehabilitation (median $\triangle \mathrm{ACQ}-0.67$ for PR only and -0.66 for $\mathrm{PR}+\mathrm{SMS}$ ), whereas no significant improvement was seen in the usual care group (median $\triangle \mathrm{ACQ}-0.25$ ) (figure 2). The median improvements in both groups were above the minimal clinically important difference (MCID) of 0.5. There was an increase in FRC in the PR only group, and a trend was observed in the $\mathrm{PR}+\mathrm{SMS}$ group. There were no significant improvements in dynamic lung function parameters, such as forced expiratory volume in $1 \mathrm{~s}\left(\mathrm{FEV}_{1}\right)$ and forced vital capacity (FVC). Aerobic capacity $\left(V_{\mathrm{O}_{2} \max }\right)$ improved only significantly in the PR only group and a trend was observed in the 
TABLE 1 baseline characteristics of study participants in three groups: pulmonary rehabilitation only (PR only), pulmonary rehabilitation+self-management support (PR+SMS) and control

\begin{tabular}{|c|c|c|c|c|}
\hline & PR only & PR+SMS & Control & p-value \\
\hline Participants n & 14 & 7 & 10 & \\
\hline Age years & $41.57 \pm 9.73$ & $41.57 \pm 12.54$ & $41.90 \pm 8.58$ & 0.996 \\
\hline Female sex $\%$ & 71.43 & 57.14 & 90.00 & 0.298 \\
\hline Weight kg & $103.25 \pm 17.76$ & $106.33 \pm 10.87$ & $100.68 \pm 17.56$ & 0.786 \\
\hline BMI $\mathrm{kg} \cdot \mathrm{m}^{-2}$ & $36.72 \pm 4.79$ & $36.82 \pm 4.96$ & $35.16 \pm 3.86$ & 0.664 \\
\hline Fat mass $\%$ & $44.67 \pm 5.90$ & $39.60 \pm 11.80$ & $44.1 \pm 4.5$ & 0.330 \\
\hline Waist circumference $\mathrm{cm}$ & $109.07 \pm 13.75$ & $114.29 \pm 8.83$ & $107.00 \pm 10.51$ & 0.458 \\
\hline Diabetes $\%$ & 7.14 & 28.57 & 0.00 & 0.133 \\
\hline Hypertension \% & 14.29 & 0.00 & 30.00 & 0.246 \\
\hline $\mathrm{PD}_{20} \mathrm{mg}$ & $0.12(0.06-1.59)$ & $0.28(0.07-0.28)$ & $0.22(0.04-0.47)$ & 0.784 \\
\hline FEV $1 \%$ & $86.93 \pm 9.35$ & $95.86 \pm 11.74$ & $82.4 \pm 16.17$ & 0.105 \\
\hline $\mathrm{FEV}_{1} / \mathrm{FVC}$ & $76.86 \pm 8.88$ & $78.71 \pm 6.79$ & $74.30 \pm 8.97$ & 0.565 \\
\hline RV \% & $78.92 \pm 15.47$ & $85.43 \pm 20.55$ & $86.80 \pm 17.86$ & 0.528 \\
\hline TLC $\%$ & $66.00 \pm 14.30$ & $68.29 \pm 11.94$ & $91.10 \pm 8.57$ & 0.262 \\
\hline RV/TLC & $27.00 \pm 5.52$ & $26.57 \pm 4.93$ & $30.60 \pm 6.24$ & 0.245 \\
\hline FRC $\%$ & $66.0 \pm 14.30$ & $68.86 \pm 11.94$ & $72.30 \pm 18.14$ & 0.621 \\
\hline$F_{\mathrm{eNO}} \mathrm{ppb}$ & $18.0(10.5-25.0)$ & $17.0(16.0-25.0)$ & $17.0(8.5-26.0)$ & 0.895 \\
\hline$V_{\mathrm{O}_{2}} \max \%$ & $51.07 \pm 17.66$ & $60.57 \pm 16.46$ & $56.50 \pm 11.27$ & 0.405 \\
\hline$A C Q$ & $2.17(1.46-2.50)$ & $1.67(1.17-1.83)$ & $2.09(1.50-2.68)$ & 0.333 \\
\hline AQLQ & $4.77(4.33-5.43)$ & $4.40(4.13-5.33)$ & $4.47(3.47-5.00)$ & 0.668 \\
\hline 6MWD m & $578.17 \pm 75.70$ & $605.78 \pm 55.95$ & $587.30 \pm 72.95$ & 0.733 \\
\hline Steps & 5997 (4024-8048) & $5616(4306-6080)$ & 7413 (2962-8155) & 0.421 \\
\hline PAL & $1.48 \pm 0.16$ & $1.43 \pm 0.09$ & $1.47 \pm 0.14$ & 0.815 \\
\hline
\end{tabular}

Data are presented as mean \pm SD or median (interquartile range), unless otherwise stated. BMI: body mass index; $\mathrm{PD}_{20}$ : doses of methacholine $(\mathrm{mg})$ leading $20 \%$ reduction in forced expiratory volume in $1 \mathrm{~s}\left(\mathrm{FEV}_{1}\right)$; FVC: forced vital capacity; RV: residual volume; TLC: total lung capacity; RV/TLC: ratio between residual volume and total lung capacity; FRC: functional residual capacity; $F_{\mathrm{eNO}}$ : fractionated exhaled nitric oxide; $V_{\mathrm{O}_{2} \max }$ : maximal oxygen uptake; $A C Q$ : asthma control questionnaire; $A Q L Q$ : asthma quality of life questionnaire; 6MWD: 6-min walking distance; PAL: physical activity level.

PR+SMS group. There was an improvement in 6-min walk distance (6MWD) in both PR only and $\mathrm{PR}+\mathrm{SMS}$ groups. The activity level only improved in the PR+SMS group (table 2).

Outcomes in pulmonary rehabilitation (PR only) versus usual care groups

Subjects in the PR only group had a significantly greater reduction in weight $(\beta=-2.193$ (CI -4.116 $-0.271) ; p=0.028)$, BMI $(\beta=-0.986$ (CI $-1.70-0.273) ; p=0.010)$ and percentage fat mass $(\beta=-1.633$ (CI $-2.888-0.377) ; \mathrm{p}=0.015)$ compared with the usual care group at 3 months and these improvements in body composition persisted during 12 months of follow up (tables 2, 3 and figure 3). At 3 months, there were no differences in asthma control or asthma quality of life between the PR only and usual care group, but during 12 months of follow up, ACQ was significantly lower in the PR only group compared with the usual care group $(\beta=-1.06$ (CI $-1.84--0.27) ; p=0.011)$. In addition, there was a significant increase in FRC and expiratory reserve volume in the PR only group compared with the usual care group at 3 months. However, these improvements were not significantly different after 12 months of follow up. Exercise capacity $\left(V_{\mathrm{O}_{2}} \max\right.$ and $\left.6 \mathrm{MWD}\right)$ improved significantly in the PR only group after 3 months of pulmonary rehabilitation, and these improvements persisted during 12 months of follow up. $\Delta$ BMI was only significantly associated with improvement in FRC ( $\beta=-4.13$ (CI $-6.24--2,01), \mathrm{p}=0.001)$, but not with ACQ ( $\beta=0.005$ (CI -0.396-0.406); $\mathrm{p}=0.979)$, ACLQ $(\beta=-0.20(\mathrm{CI}-0.60-0.19) ; \mathrm{p}=0.288)$ and $V_{\mathrm{O}_{2}} \max$ $(\beta=-1.00(\mathrm{CI}-6.25-4.25) ; \mathrm{p}=0.685)$ at 3 months. However, we found a trend for significant association of BMI with FRC $(\beta=-0.61$ (CI $-1.23-0.01) ; \mathrm{p}=0.054)$ and $V_{\mathrm{O}_{2}} \max (\beta=-1.17(\mathrm{CI}-2.38-0.037) ; \mathrm{p}=0.057)$ at 12 months, but no association with ACQ $(\beta=-0.03$ (CI $-0.12-0.05) ; \mathrm{p}=0.412)$ and AQLQ ( $\beta=-0.01$ (CI $-0.09-0.77) ; p=0.901)$ were found. We observed no significant changes in the amount of daily steps or physical activity level at 3 months, but subjects in the PR only group had significant higher amount of daily steps compared with the subjects in the usual care group after 12 months of follow up ( $\beta=3200$ (CI 1256-5144); $\mathrm{p}=0.005$ ) (tables 2,3 and figure 3 ). There were no differences observed in airway inflammation ( $F_{\mathrm{eNO}}$, sputum eosinophils and sputum neutrophils) between PR only and usual care groups after 3 and during 12 months of follow up. However, there was a significant decrease in serum leptin levels 
TABLE 2 Parameters at baseline and changes within groups after 3 months

\begin{tabular}{|c|c|c|c|}
\hline & Baseline & Change within groups after 3 months & p-value \\
\hline \multicolumn{4}{|l|}{ ACQ } \\
\hline Control & $2.09(1.50-2.68)$ & $-0.25(-0.66-0.63)$ & \\
\hline PR only & $2.17(1.46-2.50)$ & $-0.67(-1.42-0.00) .^{* *}$ & 0.113 \\
\hline $\mathrm{PR}+\mathrm{SMS}$ & $1.67(1.17-1.83)$ & $-0.66(-1.17--0.33)^{* *}$ & 0.620 \\
\hline \multicolumn{4}{|l|}{ AQLQ } \\
\hline Control & $4.47(3.47-5.00)$ & $0.12(-0.26-0.62)$ & \\
\hline PR only & $4.77(4.33-5.43)$ & $0.20(-0.33-0.84)$ & 0.758 \\
\hline$P R+S M S$ & $4.40(4.13-5.33)$ & $1.47(-0.40-1.74)$ & 0.384 \\
\hline \multicolumn{4}{|l|}{ Weight kg } \\
\hline Control & $100.7 \pm 17.56$ & $-0.1 \pm 1.7$ & \\
\hline PR only & $103.3 \pm 17.76$ & $-4.9 \pm 4.9 * *$ & 0.028 \\
\hline $\mathrm{PR}+\mathrm{SMS}$ & $106.3 \pm 10.87$ & $-10.9 \pm 8.4^{* *}$ & 0.091 \\
\hline \multicolumn{4}{|l|}{ BMI $\mathrm{kg} \cdot \mathrm{m}^{-2}$} \\
\hline Control & $35.2 \pm 3.9$ & $0.25 \pm 0.65$ & \\
\hline PR only & $36.7 \pm 4.8$ & $-1.81 \pm 1.79 * *$ & 0.010 \\
\hline $\mathrm{PR}+\mathrm{SMS}$ & $36.8 \pm 5.0$ & $-3.62 \pm 2.73^{* *}$ & 0.152 \\
\hline \multicolumn{4}{|c|}{ Waist circumference $\mathrm{cm}$} \\
\hline Control & $107.0 \pm 10.5$ & $4.67 \pm 11.96$ & \\
\hline PR only & $109.1 \pm 13.7$ & $-3.68 \pm 7.23$ & 0.173 \\
\hline $\mathrm{PR}+\mathrm{SMS}$ & $114.3 \pm 8.8$ & $-12.14 \pm 9.84^{* *}$ & 0.107 \\
\hline \multicolumn{4}{|l|}{ Fat mass $\%$} \\
\hline Control & $44.1 \pm 4.5$ & $-0.33 \pm 1.75)$ & \\
\hline PR only & $44.7 \pm 5.9$ & $-1.41 \pm 1.36^{* *}$ & 0.015 \\
\hline $\mathrm{PR}+\mathrm{SMS}$ & $39.6 \pm 11.8$ & $-2.01 \pm 3.86^{* *}$ & 0.326 \\
\hline \multicolumn{4}{|l|}{$\mathrm{FEV}_{1} \%$} \\
\hline Control & $82.4 \pm 16.2$ & $-0.22 \pm 7.5$ & \\
\hline PR only & $86.9 \pm 9.4$ & $1.0 \pm 6.2$ & 0.351 \\
\hline $\mathrm{PR}+\mathrm{SMS}$ & $95.9 \pm 11.7$ & $2.5 \pm 7.8$ & 0.808 \\
\hline \multicolumn{4}{|l|}{ FRC \% } \\
\hline Control & $72.3 \pm 18.1$ & $-1.4 \pm 8.8$ & \\
\hline PR only & $66.0 \pm 14.3$ & $9.2 \pm 8.1 *$ & 0.017 \\
\hline$P R+S M S$ & $68.3 \pm 11.9$ & $10.2 \pm 10.5$ & 0.943 \\
\hline \multicolumn{4}{|l|}{ ERV L } \\
\hline Control & $0.45 \pm 0.22$ & $0.04 \pm 0.16$ & \\
\hline PR only & $0.42 \pm 0.18$ & $0.22 \pm 0.16^{*}$ & 0.033 \\
\hline $\mathrm{PR}+\mathrm{SMS}$ & $0.53 \pm 0.23$ & $0.31 \pm 0.47$ & 0.783 \\
\hline \multicolumn{4}{|l|}{$F_{\text {eNo }} \mathrm{ppm}$} \\
\hline Control & $17.0(8.5-26.0)$ & $-0.5(-14.8-4.0)$ & \\
\hline PR only & $18.0(10.5-25.0)$ & $-0.5(-3.3-3.3)$ & 0.113 \\
\hline$P R+S M S$ & $17.0(16.0-25.0)$ & $0.5(-7.3-6.5)$ & 0.875 \\
\hline \multicolumn{4}{|l|}{$V_{\mathrm{O}_{2}} \max \%$} \\
\hline Control & $56.5 \pm 11.3$ & $-0.1 \pm 10.5$ & \\
\hline PR only & $51.1 \pm 17.7$ & $+13.2 \pm 9.2^{*}$ & 0.029 \\
\hline $\mathrm{PR}+\mathrm{SMS}$ & $60.6 \pm 11.3$ & $+11.2 \pm 13.5$ & 0.678 \\
\hline \multicolumn{4}{|l|}{ 6MWD m } \\
\hline Control & $587 \pm 73$ & $-14 \pm 51$ & \\
\hline PR only & $578 \pm 76$ & $52 \pm 40^{*}$ & 0.080 \\
\hline $\mathrm{PR}+\mathrm{SMS}$ & $606 \pm 56$ & $63 \pm 40 * *$ & 0.627 \\
\hline \multicolumn{4}{|l|}{ Steps $\mathrm{n}$} \\
\hline Control & 7413 (2962-8155) & $1281(-65-4036)$ & \\
\hline PR only & $5997(4024-8048)$ & $1008(70-2994)$ & 0.100 \\
\hline$P R+S M S$ & $5616(4306-6080)$ & $3097(1785-4740)^{* *}$ & 0.181 \\
\hline \multicolumn{4}{|l|}{ PAL } \\
\hline Control & $1.47 \pm 0.14$ & $0.04 \pm 0.08$ & \\
\hline PR only & $1.48 \pm 0.16$ & $0.00 \pm 0.18$ & 0.429 \\
\hline PR+SMS & $1.43 \pm 0.09$ & $0.11 \pm 0.08 * *$ & 0.367 \\
\hline \multicolumn{4}{|c|}{ Sputum eosinophils \% } \\
\hline Control & $0.65(0.50-2.90)$ & $1.20(0.25-3.05)$ & \\
\hline PR only & $0.65(0.05-4.30)$ & $-0.15(-2.40-1.13)$ & 0.270 \\
\hline$P R+S M S$ & $0.90(0.23-4.05)$ & $0.00(-0.83-1.05)$ & 0.680 \\
\hline
\end{tabular}


TABLE 2 Continued

Baseline

Change within groups after 3 months

p-value

$\begin{array}{ll}\text { Sputum neutrophils \% } \\ \text { Control } & 49.4(39.6-57.2) \\ \text { PR only } & 37.2(28.4-51.0) \\ \text { PR+SMS } & 29.6(23.4-57.9)\end{array}$

$-7.2(-49.1--7.2)$
$-3.6(-33.5-35.9)$
$15.1(-9.8-22.4)$

0.828

0.852

Data are presented as median (interquartile range) or mean $\pm S D$, unless otherwise stated. PR only: pulmonary rehabilitation only; PR+SMS: pulmonary rehabilitation+self-management support; $A C Q$ : asthma control questionnaire; $A Q L Q$ : asthma quality of life questionnaire; $B M I$ : body mass index; $F E V_{1}$ : forced expiratory volume in $1 \mathrm{~s}$; FRC: functional residual capacity; ERV: expiratory reserve volume; $F_{\mathrm{eNO}}$ : exhaled nitric oxide fraction; $V_{\mathrm{O}_{2} \text { max }}$ : maximal oxygen uptake; 6MWD: 6 min walking distance; PAL: physical activity level. Stated $p$-values are for difference between PR only versus control and PR+SMS versus PR only groups (ANOVA). Differences within groups tested with the paired samples Student's t-test or Wilcoxon matched pairs test. ${ }^{*}: p \leqslant 0.005$ versus baseline; ${ }^{* *}: p \leqslant 0.05$ versus baseline.

in the PR only group compared with the control group after 3 months and during 12 months of follow up (table 4). This decrease in serum leptin was significantly associated with reduction in BMI ( $\beta=9.37$ (CI 4.60-14.12); $\mathrm{p}=0.001)$.

\section{Outcomes in pulmonary rehabilitation group with versus without the use of the online} self-management support (PR only versus $P R+S M S$ )

No differences were found in weight or body composition between PR only and PR+SMS groups at 3 months (table 2). However, during 12 months of follow up, patients in the PR+SMS group had a significant lower weight $(\beta=-6.23$ (CI -11.3--1.12); $\mathrm{p}=0.021)$ and BMI $(\beta=-2.27$ (CI $-4.20-0.35)$; $\mathrm{p}=0.025)$ compared to subjects in the PR only group. In addition, there was a trend for a lower percentage fat mass in the PR+SMS group $(\beta=-2.03$ (CI -4.13-0.07); $\mathrm{p}=0.056)$ (table 3, figure 3). No statistically significant differences were observed in changes of ACQ, AQLQ, lung function, exercise capacity $\left(V_{\mathrm{O}_{2} \max }\right.$ and 6MWD) or activity level (physical activity level or daily steps) between PR+SMS and PR only group at 3 months and during 12 months of follow up. We did not find any difference in $F_{\mathrm{eNO}}$, sputum eosinophils or neutrophils between these groups at 3 months and during 12 months of follow up. Serum leptin levels decreased significantly more in the PR only group compared with the PR+SMS group at 3 months $(\beta=19.5$ (CI 5.65-33.35); $\mathrm{p}=0.009$ ) and this difference persisted during 12 months of follow up ( $\beta=20.66$ (CI 7.1034.21); $\mathrm{p}=0.006$ ). However, we observed no differences in any of other inflammatory markers at 3 months or 12 months of follow up (table 4).

\section{Exacerbations}

No difference in the proportion of patients with an asthma exacerbation during the 3 months intervention period were found between the PR only group and the control group ( $16.7 \%$ versus $55.6 \%$; $\mathrm{p}=0.16)$. In

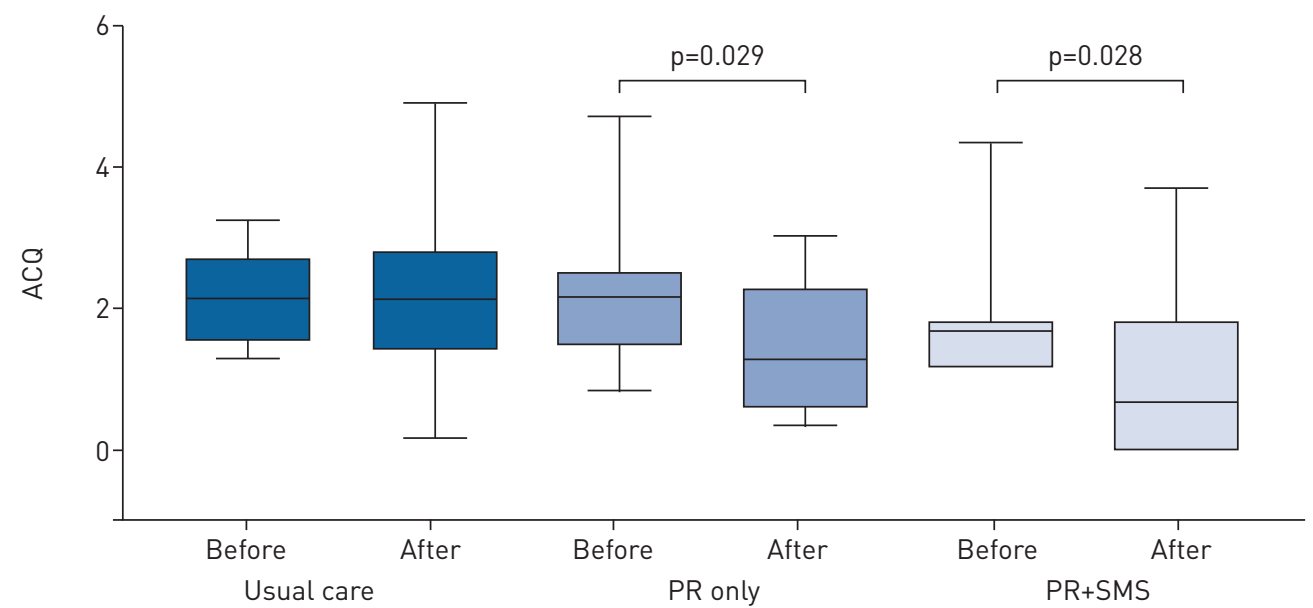

FIGURE 2 Changes in asthma control (Asthma Control Questionnaire (ACQ)) in each group after 3 months. Data are presented as median (interquartile ranges); $p$-value for ANOVA. 
TABLE 3 Change after 12 months.

\begin{tabular}{|c|c|c|c|}
\hline & $\begin{array}{l}\text { Change at } 12 \text { months versus } \\
\text { baseline within groups }\end{array}$ & $\begin{array}{l}\text { Mean difference between the groups over } \\
\text { time }^{\#} \beta \text {-coefficient }(95 \% \mathrm{CI})\end{array}$ & p-value \\
\hline \multicolumn{4}{|l|}{$A C Q$} \\
\hline Control & $0.91(-0.49-2.50)$ & & \\
\hline PR only & $-0.59(-1.62-0.22)$ & $-1.06(-1.84 ;-0.27)$ & 0.011 \\
\hline $\mathrm{PR}+\mathrm{SMS}$ & $-1.05(-0.84--1.87)$ & $-0.34(-0.95-0.27)$ & 0.252 \\
\hline \multicolumn{4}{|l|}{ AQLQ } \\
\hline Control & $-0.14(-0.62-1.37)$ & & \\
\hline PR only & $0.59(-0.46-1.93)$ & $0.28(-0.65-1.22)$ & 0.537 \\
\hline $\mathrm{PR}+\mathrm{SMS}$ & $0.60(-0.44-2.50)$ & $0.32(-0.64-1.29)$ & 0.483 \\
\hline \multicolumn{4}{|l|}{ BMI $\mathrm{kg} \cdot \mathrm{m}^{-2}$} \\
\hline Control & $0.78 \pm 1.29$ & & \\
\hline PR only & $-2.15 \pm 2.85$ & $-2.25(-3.38--1.11)$ & 0.001 \\
\hline $\mathrm{PR}+\mathrm{SMS}$ & $-4.90 \pm 6.11$ & $-2.27(-4.20--0.35)$ & 0.025 \\
\hline \multicolumn{4}{|c|}{ Waist circumference $\mathrm{cm}$} \\
\hline Control & $-0.33 \pm 3.33$ & & \\
\hline PR only & $-4.88 \pm 7.77$ & $-3.25(-8.86-2.35)$ & 0.239 \\
\hline $\mathrm{PR}+\mathrm{SMS}$ & $-12.5 \pm 17.87$ & $-7.07(-15.91-1.78)$ & 0.109 \\
\hline \multicolumn{4}{|l|}{ Fat mass $\%$} \\
\hline Control & $1.80 \pm 1.11$ & & \\
\hline PR only & $-3.62 \pm 4.41$ & $-2.63(-4.42--0.84)$ & 0.008 \\
\hline $\mathrm{PR}+\mathrm{SMS}$ & $-6.30 \pm 8.44$ & $-2.03(-4.13-0.07)$ & 0.056 \\
\hline \multicolumn{4}{|l|}{ FEV $_{1} \%$} \\
\hline Control & $1.43 \pm 6.32$ & & \\
\hline PR only & $4.50 \pm 10.49$ & $0.24(-5.40-5.87)$ & 0.931 \\
\hline $\mathrm{PR}+\mathrm{SMS}$ & $0.00 \pm 6.67$ & $3.37(-4.41-11.14)$ & 0.368 \\
\hline \multicolumn{4}{|l|}{ FRC $\%$} \\
\hline Control & $8.83 \pm 26.32$ & & \\
\hline PR only & $7.38 \pm 13.50$ & $12.2(7.91-16.5)$ & $<0.001$ \\
\hline $\mathrm{PR}+\mathrm{SMS}$ & $10.8 \pm 5.89$ & $1.37(-6.64-9.38)$ & 0.702 \\
\hline \multicolumn{4}{|l|}{$V_{0} \max \%$} \\
\hline Control & $1.33 \pm 14.07$ & & \\
\hline PR only & $11.7 \pm 15.65$ & $12.04(1.99-22.08)$ & 0.022 \\
\hline $\mathrm{PR}+\mathrm{SMS}$ & $7.50 \pm 3.70$ & $-7.83(-19.58-3.92)$ & 0.174 \\
\hline \multicolumn{4}{|l|}{ 6MWD m } \\
\hline Control & $-40.38 \pm 53.99$ & & \\
\hline PR only & $40.29 \pm 53.52$ & $58.0(16.9-99.1)$ & 0.009 \\
\hline $\mathrm{PR}+\mathrm{SMS}$ & $81.40 \pm 59.45$ & $10.5(-25.98-46.91)$ & 0.539 \\
\hline \multicolumn{4}{|l|}{ Steps $\mathrm{n}$} \\
\hline Control & $987(-1621-5747)$ & & \\
\hline PR only & 5591 (3480-4491) & $3200(1256-5144)$ & 0.005 \\
\hline $\mathrm{PR}+\mathrm{SMS}$ & $902(-282-2080)$ & $740(-1614-3095)$ & 0.388 \\
\hline
\end{tabular}

Data are presented as median (interquartile range) or mean $\pm S D$, unless otherwise stated. PR only: pulmonary rehabilitation only; PR+SMS: pulmonary rehabilitation+self-management support; $A C Q$ : asthma control questionnaire; $A Q L Q$ : asthma quality of life questionnaire; $B M I$ : body mass index; $F E V_{1}$ : forced expiratory volume in $1 \mathrm{~s}$; FRC: functional residual capacity; $V_{\mathrm{O}_{2} \text { max }}$ : maximal oxygen uptake; 6MWD: 6 min walking distance. $p$-value for difference between PR only versus control and PR+SMS versus PR only groups over time (repeated measurements (mixed model)). * : effect sizes adjusted for time, parameter baseline value and sex.

addition, no difference in the proportion of patients with an exacerbation was observed in PR+SMS versus PR only group. During the 12 months of follow-up, a higher rate of exacerbations was observed in the control group compared to the PR only group ( $\beta$ (poisson rate) $=0.839$ (CI $0.116-1.563$ ); $p=0.023$; RR 2.314 (CI 1.123-4.773)) whereas no significant difference in exacerbation rate was seen between $\mathrm{PR}+\mathrm{SMS}$ group and the PR only group ( $\beta$ (poisson rate) $=0.319$ (CI $-0.811-1.449) ; \mathrm{p}=0.580$; RR 1.376 (CI 0.444-4.259)).

\section{Discussion}

In this pragmatic study, we investigated the short- and long-term effects of a 3-months high-intensity pulmonary rehabilitation programme in obese patients with suboptimally controlled asthma. The majority 

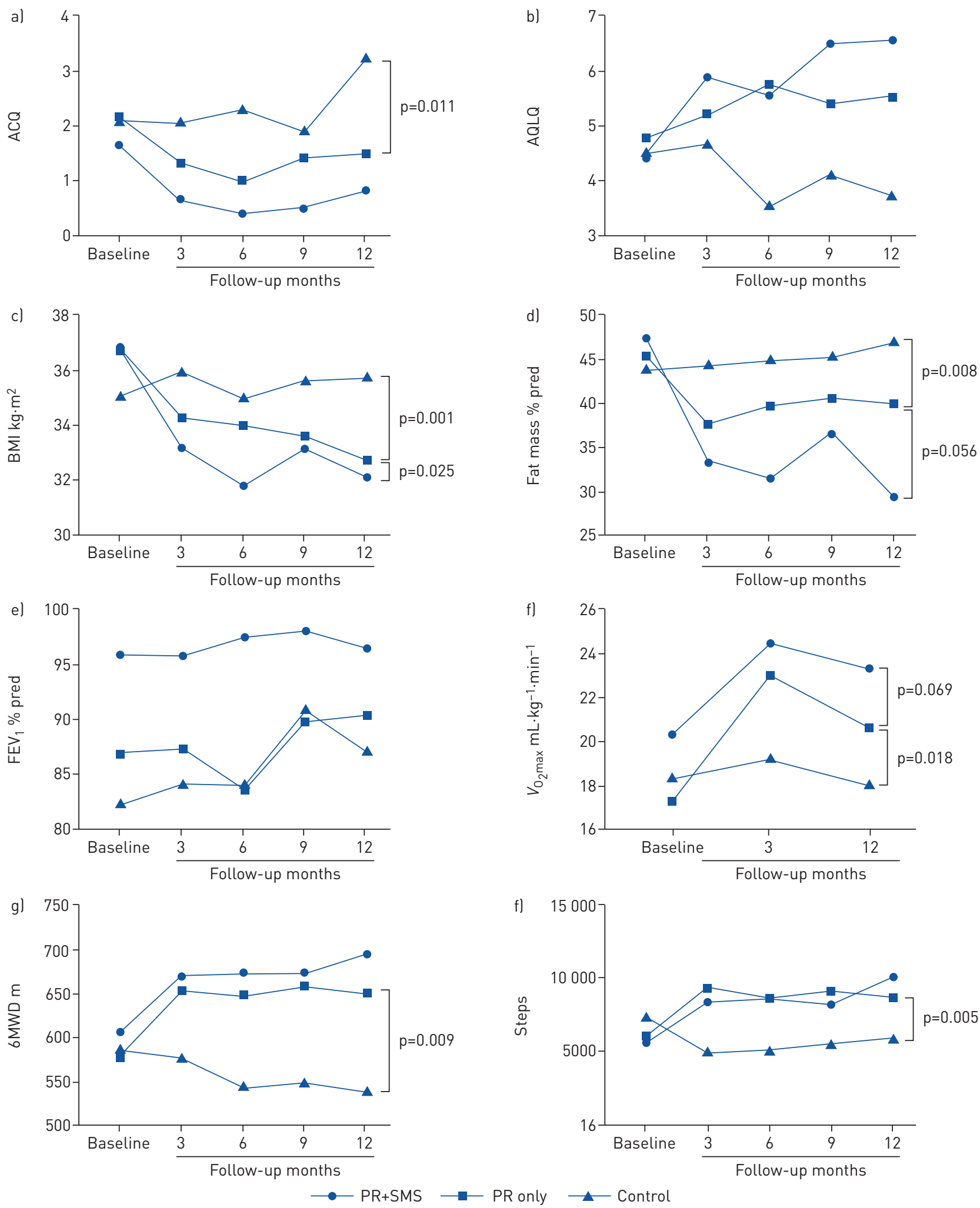

FIGURE 3 Changes over time in a) Asthma Control Questionnaire (ACQ), b) asthma-related quality of life (AQLQ), c) body mass index (BMI), d) fat mass, e) forced expiratory volume in $1 \mathrm{~s}\left(\mathrm{FEV}_{1}\right), \mathrm{f}$ ) maximum exercise capacity $\left(V_{\mathrm{O}_{2} \text { max }}\right), \mathrm{g}$ ) 6-min walk distance (6MWD), and h) steps. Dots present mean or median values. $p$-value for difference between groups over time (repeated measurements (mixed model)).

of the patients had an uncontrolled type 2 asthma (GINA 4) and a low aerobic capacity at the time of inclusion. Nevertheless, HIIT in this group of patients was found to be feasible. Moreover, this short-term pulmonary rehabilitation programme resulted in a clinically relevant improvement of asthma control and 
TABLE 4 Change of systemic inflammatory markers after 3 months and 12 months

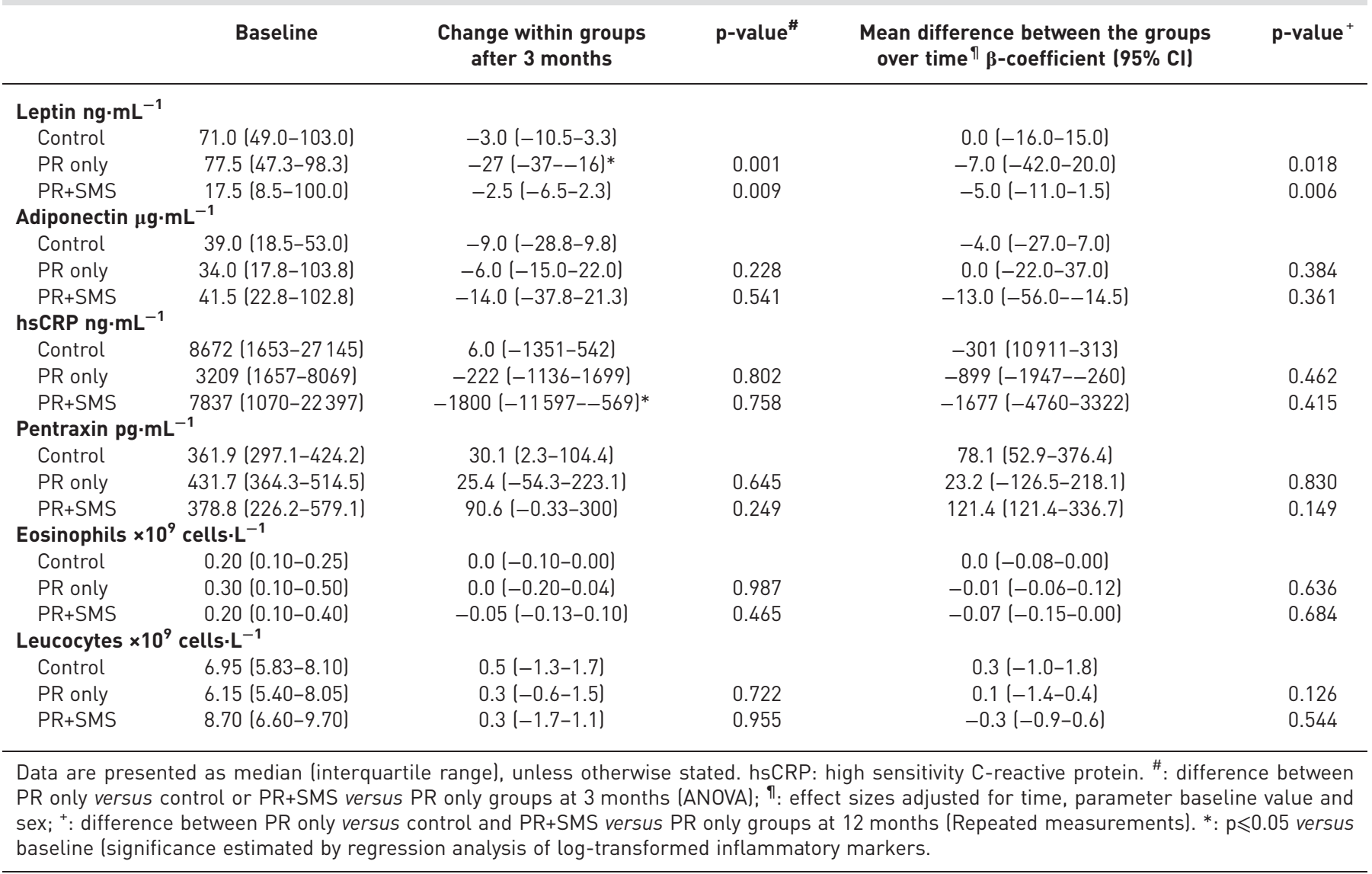

marked improvements in body composition, aerobic capacity and lung function in a short period of 3 months. More importantly, the positive effects on asthma control (ACQ), BMI, exercise capacity and physical activity persisted during the 12 months of follow-up period. Although we did not find any difference in the primary outcome, asthma control, between the PR only and PR+SMS groups at 3 months, we demonstrated that adding an internet-based self-management programme on top of the pulmonary rehabilitation programme results in better weight management over time. The outcomes of this study emphasise the feasibility and the importance of lifestyle modification in this particular group of patients.

Despite the relevance of weight loss in asthmatics with obesity, there are only few randomised controlled trials available about weight-loss interventions in these patients [24, 25]. The first studies included only dietary interventions [26] or diet combined with weight-loss medication [27]. Although these interventions resulted in a significant weight loss and improvements in asthma symptoms in the short-term, information on the persistence of these effects over a long period was lacking. The study of Sсотт et al. [8] was the first randomised study comparing a combined dietary and exercise intervention with diet or exercise alone. This study demonstrated that exercise alone had no effect on weight loss or asthma symptoms, and that a combined diet/exercise intervention should be the choice in obese asthmatics [8]. However, in this study, not only obese but also overweight subjects were included and the level of asthma control was better compared with that in the present study (ACQ 1.36 versus 2.0). The mean weight loss was $8.3 \%$ after 10 weeks of intervention, including a very strict caloric restriction of $885-$ $1170 \mathrm{kcal} \cdot \mathrm{day}^{-1}$ and an exercise programme with aerobic and resistance training. In contrast, Ma et al. [28] found modest weight loss (5\% and 4\%) after 6 and 12 months of lifestyle intervention, including a dietary restriction of $1200 \mathrm{kcal} \cdot \mathrm{day}^{-1}$ and at least $150 \mathrm{~min}$ of moderate intensity physical activity per week in 330 obese adults with uncontrolled asthma. The effects on asthma control were disappointing. The authors concluded that a weight loss of $10 \%$ or greater may be required for a clinically significant improvement in asthma outcomes [28]. More recently, FreITAS et al. [9] demonstrated that a 3-month weight-loss programme with caloric restriction of approximately $1300 \mathrm{kcal} \cdot \mathrm{day}^{-1}$, aerobic and resistance training results in significant improvements in body composition, asthma control, aerobic capacity, lung function, airway and systemic inflammation in obese adults with asthma. In the present study, a less strict 
caloric restriction of $1500 \mathrm{kcal} \cdot \mathrm{day}^{-1}$ combined with HIIT (intensity $\pm 90 \%$ of $V_{\mathrm{O}_{2} \max }$ ) resulted in a mean weight loss of $5 \%$ in the PR only group and $12 \%$ in the PR+SMS group at 3 months, with persistent improvements in asthma control, BMI and exercise capacity in the majority of patients at 12 months.

Obesity is characterised by low-grade systemic inflammation with increased production of pro-inflammatory cytokines. In this study, we did not find any reduction in pro-inflammatory cytokines, like high-sensitivity C-reactive protein or pentraxin, but we have demonstrated that there was a decrease in serum leptin levels in participants immediately after the pulmonary rehabilitation programme and during 12 months of follow up. This decrease in serum leptin appeared strongly associated with the persistent decrease of BMI during 12 months of follow-up in the PR only group. Although an intervention period of 3 months may appear short to achieve a lifestyle change, we have demonstrated that a short-term well-designed multidisciplinary pulmonary rehabilitation programme could result in long-term benefits. The positive effects on weight, aerobic capacity and symptoms could encourage patients to maintain their diet and exercise for a longer period. In addition, the use of an internet-based self-management programme during and after the pulmonary rehabilitation programme could be supportive for long-term adherence. As we have showed in the present study, compared with non-users, users of the self-management support programme on average had a significant lower BMI after 12 months of follow up. The role of such innovative approaches in the management of asthma and obesity should be further explored [29-31].The implementation of the new HIIT exercise programme was well tolerated and successful in this group of patients who are limited by their weight as well as by their asthma. In addition, the rate of exacerbations was not higher in the intervention group, indicating that HIIT did not negatively affect asthma control. To our knowledge, this is the first study showing that HIIT is feasible in obese persons with suboptimal controlled asthma. Furthermore, it has been shown that HIIT is perceived to be more pleasant than moderate intensity continuous exercise [32]. This may improve the adherence to exercise and promote health benefit over a longer period.

Another important issue is the cost-effectiveness of such rehabilitation programmes. The cost of a 3-month rehabilitation programme is approximately $€ 3000$ per person. The costs of an exacerbation varies between $€ 500$ and 3000 depending on the extra visits, emergency room visits and the requirement of a clinical admission. So, depending on the severity of the exacerbations and the long-lasting effect of the programme, pulmonary rehabilitation could ultimately be cost-effective. In the Netherlands, this programme is therefore only available for more severe, uncontrolled patients. However, the present study was not designed or powered to calculate cost-effectiveness.

Our study has some limitations. Firstly, this study comprises a relatively small sample (figure 1). It was very difficult to recruit suitable candidates for this study. Most eligible patients were unable to participate because of work or other reasons. Despite small group sizes, our explorative study suggests that pulmonary rehabilitation is effective and that self-management support contributes to maintaining long-term effects. A larger study is needed to corroborate these results with sufficient power. Our study participants were predominantly female, and able and motivated to participate in this programme which could have resulted in a selection bias. However, in these kinds of studies, motivation for participation is an important requirement for success. In addition, diets were not tailored to each patient, which could be a pitfall. This could explain the differences in weight loss between the patients; especially male patients, who could have lost much more weight with this amount of caloric restriction. However, our diet was less strict compared with other studies $[8,9]$. Finally, we have used an integrated pulmonary rehabilitation programme, and were unable to determine the contribution of the four individual components of this programme to the outcome. We have shown that the reduction of BMI is especially associated with improvements in lung function, but not with the improvement of asthma control. This indicates that it is not "just a matter of weight loss", but that the other components of the pulmonary rehailitation programme, like exercise and psychological intervention are probably at least equally important to achieve improvements in asthma control.

The present study, despite its limitations, is the first demonstrating that a short-term multidisciplinary pulmonary rehabilitation programme with HIIT and the use of an internet-based self-management programme is feasible and effective in both the short and long term, in suboptimal controlled asthmatics with obesity. Such well-designed pulmonary rehabilitation programmes should be considered in the treatment of obese asthmatics.

Acknowledgements: We wish to thank all employees of the Depts of Physiotherapy, Dietetics, Medical Psychology, Lung Function and Dept of Clinical Chemistry at the Franciscus Gasthuis \& Vlietland, Rotterdam, the Netherlands. We are grateful for the help of A. van Schadewijk and A.C. van der Linden (Leiden University Medical Center, Leiden, the Netherlands) in the analysis of serum markers of systemic inflammation.

Conflict of interest: Y. Türk reports grants from GSK, TEVA, Novartis and Chiesi, during the conduct of the study. W. Theel has nothing to disclose A. van Huisstede has nothing to disclose. G-J.M. van de Geijn reports personal fees for 
lectures and non-financial support (travel and accommodation reimbursement, reagents and equipment for research) from Beckman Coulter, outside the submitted work. E. Birnie has nothing to disclose. P.S. Hiemstra has nothing to disclose. J.K. Sont has nothing to disclose. C. Taube has nothing to disclose. G-J. Braunstahl reports grants from GSK, Teva, Novartis and Chiesi, during the conduct of the study; personal fees from ALK Abello, GSK, AstraZeneca, Sanofi, Chiesi and Novartis, outside the submitted work.

Support statement: This work was supported by Chiesi Farmaceutici, Novartis Pharma, GlaxoSmithKline and Teva Pharmaceutical Industries. Funding information for this article has been deposited with the Crossref Funder Registry.

\section{References}

Beuther DA. Obesity and asthma. Clin Chest Med 2009; 30: 479-488.

2 Camargo CA J, Weiss ST, Zhang S, et al. Prospective study of body mass index, weight change, and risk of adult-onset asthma in women. Arch Intern Med 1999; 159: 2582-2588.

3 Farah CS, Kermode JA, Downie SR, et al. Obesity is a determinant of asthma control independent of inflammation and lung mechanics. Chest 2011; 140: 659-666.

4 Rasmussen F, Lambrechtsen J, Siersted HC, et al. Low physical fitness in childhood is associated with the development of asthma in young adulthood: the Odense schoolchild study. Eur Respir J 2000; 16: 866-870.

5 van ' $t$ Hul AJ, Frouws S, van den Akker E, et al. Decreased physical activity in adults with bronchial asthma. Respir Med 2016; 114: 72-77.

6 Groth SW, Rhee H, Kitzman H. Relationships among obesity, physical activity and sedentary behavior in young adolescents with and without lifetime asthma. J Asthma 2016; 53: 19-24.

7 Turk Y, van Huisstede A, Franssen FME, et al. Effect of an outpatient pulmonary rehabilitation program on exercise tolerance and asthma control in obese asthma patients. J Cardiopulm Rehabil Prev 2017; 37: 214-222.

8 Scott HA, Gibson PG, Garg ML, et al. Dietary restriction and exercise improve airway inflammation and clinica outcomes in overweight and obese asthma: a randomized trial. Clin Exp Allergy 2013; 43: 36-49.

9 Freitas PD, Ferreira PG, Silva AG, et al. The role of exercise in a weight-loss program on clinical control in obese adults with asthma. a randomized controlled trial. Am J Respir Crit Care Med 2017; 195: 32-42.

10 Turk Y, Theel W, Kasteleyn MJ, et al. High intensity training in obesity: a meta-analysis. Obes Sci Pract 2017; 3: 258-271.

11 Global Initiative for Asthma. Global Strategy for Asthma Management and Prevention 2020. www.ginaasthma.org.

12 Juniper EF, O'Byrne PM, Guyatt GH, et al. Development and validation of a questionnaire to measure asthma control. Eur Respir J 1999; 14: 902-907.

13 Juniper EF, Guyatt GH, Cox FM, et al. Development and validation of the Mini Asthma Quality of Life Questionnaire. Eur Respir J 1999; 14: 32-38.

14 Miller MR, Hankinson J, Brusasco V, et al. Standardisation of spirometry. Eur Respir J 2005; 26: 319-338.

15 Ross RM. ATS/ACCP statement on cardiopulmonary exercise testing. Am J Respir Crit Care Med 2003; 167: 1451.

16 Grundy SM, Brewer HB, Jr., Cleeman JI, et al. Definition of metabolic syndrome: Report of the National Heart, Lung, and Blood Institute/American Heart Association conference on scientific issues related to definition. Circulation 2004; 109: 433-438.

17 Thoracic S A, Respiratory S E. ATS/ERS recommendations for standardized procedures for the online and offline measurement of exhaled lower respiratory nitric oxide and nasal nitric oxide, 2005. Am J Respir Crit Care Med 2005; 171: 912-930.

18 de Groot S, Nieuwenhuizen MG. Validity and reliability of measuring activities, movement intensity and energy expenditure with the DynaPort MoveMonitor. Med Eng Phys 2013; 35: 1499-1505.

19 Kips JC, Fahy JV, Hargreave FE, et al. Methods for sputum induction and analysis of induced sputum: a method for assessing airway inflammation in asthma. Eur Respir J 1998; 11: Suppl. 26: 9S-12S.

20 Kips JC, Peleman RA, Pauwels RA. Methods of examining induced sputum: do differences matter? Eur Respir J 1998; 11: 529-533.

21 Paggiaro PL, Chanez P, Holz O, et al. Sputum induction. Eur Respir J 2002; 20: Suppl. 37: 3s-8s.

22 ten Brinke A, de Lange C, Zwinderman AH, et al. Sputum induction in severe asthma by a standardized protocol: predictors of excessive bronchoconstriction. Am J Respir Crit Care Med 2001; 164: 749-753.

23 Brooks D, Solway S, Gibbons WJ. ATS statement on six-minute walk test. Am J Respir Crit Care Med 2003; 167: 1287.

24 Moreira A, Bonini M, Garcia-Larsen V, et al. Weight loss interventions in asthma: EAACI evidence-based clinical practice guideline (part I). Allergy 2013; 68: 425-439.

25 Adeniyi FB, Young T. Weight loss interventions for chronic asthma. Cochrane Database Syst Rev 2012; 7: CD009339.

26 Stenius-Aarniala B, Poussa T, Kvarnstrom J, et al. Immediate and long term effects of weight reduction in obese people with asthma: randomised controlled study. BMJ 2000; 320: 827-832.

27 Dias-Junior SA, Reis M, de Carvalho-Pinto RM, et al. Effects of weight loss on asthma control in obese patients with severe asthma. Eur Respir J 2014; 43: 1368-1377.

28 Ma J, Strub P, Xiao L, et al. Behavioral weight loss and physical activity intervention in obese adults with asthma. A randomized trial. Ann Am Thorac Soc 2015; 12: 1-11.

29 Ahmed S, Ernst P, Bartlett SJ, et al. The effectiveness of web-based asthma self-management system, My Asthma Portal (MAP): a pilot randomized controlled trial. J Med Internet Res 2016; 18: e313.

30 van Gaalen JL, van Bodegom-Vos L, Bakker MJ, et al. Internet-based self-management support for adults with asthma: a qualitative study among patients, general practitioners and practice nurses on barriers to implementation. BMJ Open 2016; 6: e010809.

31 Newhouse N, Martin A, Jawad S, et al. Randomised feasibility study of a novel experience-based internet intervention to support self-management in chronic asthma. BMJ Open 2016; 6: e013401.

32 Kong Z, Fan X, Sun S, et al. Comparison of high-intensity interval training and moderate-to-vigorous continuous training for cardiometabolic health and exercise enjoyment in obese young women: a randomized controlled trial. PLoS One 2016; 11: e0158589. 